\title{
A musicalidade flamenca de João Cabral
}

Everton Barbosa Correia (UNICAMP)

RESUMO: Dado que poesia de João Cabral de Melo Neto se constituiu como uma das mais significativas da literatura brasileira, interessa distinguir no contexto da modernidade como a dialética do localismo versus cosmopolitismo se processa naquela obra, produzida em larga medida na Espanha e cuja tematização comporta simultaneamente elementos de nacionalidade e de universalismo. Daí cumpre investigar como se manifesta tal contradição, considerando a musicalidade dos poemas que tematizam o flamenco - expressão da Andaluzia -, coligidos no livro Museu de tudo. A partir do diálogo que os poemas estabelecem entre si, espero chegar numa compreensão particular da obra, já que a rítmica ali em curso traz elementos da cultura popular hispânica que servem aos princípios de composição do poeta brasileiro.

PALAVRAS-CHAVE: Poesia brasileira moderna; João Cabral de Melo Neto; Cosmopolitismo; Musicalidade flamenca.

ABSTRACT: It would be interesting to distinguish João Cabral de Melo Neto's work in context of modernity, since it was constituted like one of the most significant of Brazilian literature. It means to analyze how localism versus cosmopolitism dialectic is processed in that work, produced largely in Spain, whose subject matter include simultaneous facts of nationality and universalism. Because of that, it has to be investigated how such contradiction express itself, considering the musicianship of poems collected in Museu de tudo deal with flamenco - Andaluzia's expression. I hope to find a particular comprehension of work, from the dialog that poems establish to each other, due to rhythm current there to bring elements of popular Spanish culture, that serve to Brazilian Poet's compositions principles.

KEYWORDS: Modern Brazilian poetry; João Cabral de Melo Neto; Cosmopolitism; Flamenco musicianship.

Para alguém que passou toda uma vida a renegar os princípios melódicos que animam o fazer poético, é no mínimo controvertido tematizar uma forma musical, tal como acontece com João Cabral de Melo Neto quando versa sobre o flamenco. Mais estranho seria se ele escolhesse uma outra forma musical, já que apenas o frevo e o maracatu aparecem episodicamente na sua obra como remissões à música brasileira. Em relação à música estrangeira, sua indiferença não é menor, mas se revela de outra maneira quando nos voltamos para a música vinda da Andaluzia. 
Também é verdade que a tradição literária que se constitui a partir do romantismo desenvolve um certo gosto pela musicalidade inerente à feitura dos versos, o que, sob certa ótica, se radicaliza na produção dos autores de língua portuguesa e que o poeta pernambucano evita a todo custo. Assim, ao mesmo tempo em que o poeta se esquiva de uma certa tradição - afeita à música -, reivindica para si uma filiação noutra tradição - afim à plástica -, e mais próxima da poesia espanhola. De modo que, ao falar doflamenco, não é só uma expressão musical que está sendo acionada, mas também uma tradição popular que conjuga, a um só tempo, elementos visuais e verbais à expressão musical. Daí resulta uma modalidade de texto que se faz, simultanemente, em diálogo com a música e com a dança.

Além disso, João Cabral sempre esteve às voltas com expressões populares, o que pode ser percebido no plano formal pela sua simpatia às redondilhas $\mathrm{e}$ tematicamante na produção que encerra o Tríptico do Capibaribe, para ficarmos em poucos exemplos. Todas essas considerações ganham uma outra dimensão quando pensadas em função de uma expressão popular espanhola, que, sendo simpática ao autor, é estrangeira. Assim, o poeta recoloca noutros moldes uma questão que já havia sido levantada, inicialmente, na época do romantismo brasileiro e que passa pela interseção entre o nacional e o cosmopolita. Acontece que, pelo próprio ofício de diplomata, o poeta precisaria estar em contato com outras culturas. O que parece complicado é quando ele passa a assimilar parte dessa cultura para sedimentar uma expressão própria, das mais representativas na poesia brasileira.

Mais curioso ainda é o momento em que ele passa a tematizar sistematicamente o flamenco. Da sinuosa trajetória que a obra de João Cabral de Melo Neto segue, muito chama a atenção o livroMuseu de tudo, pela ordem de publicação - bem no meio do seu percurso cronológico -, e também por sua característica um tanto difusa, que, numa primeira leitura, foge aos princípios preconizados pelo autor. Ou ainda, pelo próprio poema de abertura, que sugere um balanço da obra e dá título ao livro.

O equilíbrio e a objetividade que marcam tão pontualmente a obra de João Cabral parecem adquirir outros contornos a partir daí, quando vai se percebendo uma abertura daquele rigor tão imperativo que distinguia sua obra em todas as suas dimensões. Neste caso, se há um estilo que atravessa o livro, podemos percebê-lo mais 
claramente no interior de cada poema, mas isso não vai acontecer igualmente na sua estruturação.

Este livro ocupa, pois, um lugar todo especial na obra do autor, uma vez que amplia sua identidade poética e recupera, ao mesmo tempo, alguns dos elementos que lhe são distintivos. Por isso, o livro resguarda alguns procedimentos que ficaram reconhecidos como próprios da obra cabralina, mas sem se restringir a eles, tais como: aproximação entre a cultura brasileira e a espanhola; uma exploração social cujo correspondente na linguagem se faz imperativo, como podemos ver no poema:

El cante hondo

This is the way the world ends Not with a bang but a whimper T.S. Eliot

O cante hondo às mais das vezes desconhece essa distinção: o seu lamento mais gemido acaba em explosão.

Tão retesada é sua tensão, tão carne viva seu estoque, que ao desembainhar-se em canto rompe a bainha e explode.

Uma informação válida sobre o poema é que sua realização se ocupa em converter um objeto de representação em outro, uma vez que "O cante hondo" já é, por si mesmo, um objeto de representação que recupera a cultura popular mais remota. Através da mistura entre ciganos e outras gentes vividas na Andaluzia, o canto traduz noutra esfera um tipo de representação que remete de pronto à situação existencial de um povo, cujos meios de expressão lhe caracterizam, sobretudo, porque o que está sendo sufocado apresenta esse povo em estado de dilatação máxima, que é próprio do canto e passa a ser também de quem se reconhece nele.

Se o título do poema serve, por um lado, para marcar a posição do poeta em relação ao país estrangeiro de sua maior predileção, por outro, estabelece um diálogo entre o título e o texto que se segue. De modo que o estranhamento suscitado de início tem uma duração no poema que o constitui integralmente, do título ao último verso. Ou 
seja, se a explosão anunciada já na epígrafe provoca um estado de suspensão, o poema retém sua tensão até explodir, tomando, portanto, o caminho inverso ao enunciado.

Nesse poema de João Cabral, quando aparece a palavra "explosão" provoca-se uma rima forçada com "distinção", rompendo a mesura dos demais versos. O verso distinto na primeira estrofe é, portanto, aquele que explode internamente no poema. A rima entre "distinção" e "explosão" reverbera na palavra "tensão", criando uma cadeia significativa que serve de mote para os demais versos. A pobreza da rima entre o segundo e o quarto verso da primeira estrofe vai ser coberta pela rima toante entre o segundo e o quarto da segunda estrofe, como se houvesse noutro plano o mesmo movimento da explosão contida. Por outra, o estoque carnal do canto é que o explode.

A apreciação da musicalidade na obra cabralina, tão controvertida neste poema quanto em qualquer outro, aqui merece uma atenção especial. Pois, se as rimas toantes e os octossílabos dificultam a cursividade dos versos, sua sonoridade fica ainda mais intricada pelo uso quase excessivo das oclusivas. Ao que as sibilantes respondem em sentido inverso, reproduzindo noutra esfera a contradição expressa anteriormente, que poderíamos resumir como caracterizada entre dois pólos, o da dilatação e o da contenção. Na primeira estrofe há uma predominância das sibilantes, mais evidenciada no dístico: "O cante hondo às mais das vezes, desconhece essa distinção", até que o poema explode no quarto verso, como se houvesse um sussurro que prepara, na verdade, a explosão contida de que se constitui o poema. A partir daí, há um maior equilíbrio entre essas duas bases sonoras, em que o ribombar das oclusivas recebe como indumentária as sibilantes, que atenuam o seu barulho e lhes dão um som quase melódico. Uma interpretação possível para isso seria a de que essa ambivalência mimetizasse a explosão contida de que o poema se constitui em sua própria expressão.

Gostaria ainda de lembrar de dois outros poemas que enfeixam o Museu de tudo e dialogam diretamente com "El cante Hondo", para que, assim, cheguemos a uma adjetivação mais precisa desse canto e tenhamos fios mais amplos da tessitura que o poeta engenha, seguindo a ordem de publicação no livro:

Ainda el cante flamenco

É a música desejada

como o que não adormece: 
o mais contrário do embalo

e do canto emoliente.

$\mathrm{Na}$ Andaluzia esse canto

insonífero se atende:

a contrapelo, esfolado,

arrepiando a alma e o dente.

Salvo o primeiro dístico em que se mantém a tensão já anunciada, aqui o autor parece ter buscado uma expressão bem mais espontânea, sob uma tonalidade bem menos rígida do que a do poema anteriormente analisado, inclusive pela disposição dos versos numa única estrofe. Outra oposição formal importante é a de que os versos daquele poema são em sua maioria octossílabos, apenas o quarto verso tem seis sílabas; já aqui o metro utilizado é o redondilho, o que também contribui para a impressão de um ritmo mais solto em cada um dos versos, que reverbera no poema como um todo.

Se esta é a primeira impressão que se depreende das informações técnicas mais visíveis, ao longo do poema uma outra compreensão vai se configurando em compasso com o enunciado referencialmente expresso. Nesta linha de raciocínio, o quarto verso traz uma palavra que se destaca das demais pelo inusitado em meio a um vocabulário excessivamente simples, dado pelas outras palavras. "Emoliente" chama ainda mais a atenção pelo tom distenso, quando no nível semântico o enunciado aponta para outro lado. Como se a expressão pretendida no poema repousasse sobre uma suposta contradição, a de uma melodia maleável que encobre um sentido duro. De alguma maneira podemos entrever esta contradição formal como uma tradução doflamenco noutro nível que, sugerindo um lamento choroso, não apazigua e nem conforta o sujeito, mas, ao invés disso, acende-o, o arrepia, deixa-o por inteiro ligado em vez de embalado ou adormecido.

Trata-se, portanto, de um canto para manter-se acordado, que se ouve pelo avesso, todo aberto, abrindo o que há de mais interno, a alma, e também sua expressão mais exterior, o dente, não em sorriso, mas expandindo o canto no que ele tem de esfolado, a contrapelo, embora assim não se pareça à primeira vista. Noutras palavras, $o$ poeta se empenha em demonstrar como o canteflamenco pode ser visto por diversas camadas, em cada um dos poemas abordados, o que análise em curso tenta reproduzir, acompanhando a exploração mais minuciosamente formal do som incrustado na poesia até sua configuração lexical e semântica. Assim, teríamos alguns aspectos do mesmo 
canto, observados por vários ângulos. Nessa medida, cumpre também pontuar que gradativamente o autor vai passando de uma exploração mais material do canto, tal como vimos até aqui, para uma escritura de feição mais abstrata - já que passa por filtros muito próprios à sua poesia -, levando-nos a outra compreensão do flamenco e da sua musicalidade, que se estende a da poesia cabralina, tal como apresenta o poema que se segue.

Habitar o flamenco

Como se habita uma cidade se pode habitar o flamenco: com sua linguagem, seus nativos, seus bairros, sua moral, seu tempo.

\footnotetext{
A linguagem: um falar com coisas e jamais do oito mas do oitenta; seus nativos: toda uma gente que existe espigada e morena; seus bairros: todos os sotaques em que divide seus acentos; sua moral: a vida que se abre e se esgota num instante intenso; seu tempo: borracha que estica em segundos de passar lento, lento de sesta, sesta insone em que se está aceso e extremo.
}

Este poema se efetiva por reproduzir o flamenco em suas múltiplas dimensões e não exclusivamente como canto -, uma vez que se faz em função de sua linguagem, seus nativos, bairros, moral e tempo. Trata-se, portanto, de uma expressão muito bem demarcada nas suas inúmeras variantes. Por outro lado, considerando o poema como uma expressão própria de João Cabral, que revela algo de sua musicalidade intrínseca, a qual pode ser habitada, parece-nos uma realização um tanto enigmática. Pois, ainda que tomemos uma definição muito ampla de música, a saber, uma sucessão de sons arranjados que decorre no tempo, mesmo assim teríamos considerável dificuldade em precisar o flamenco de João Cabral, que se materializa num espaço a ser habitado com linguagem, nativos, bairros, moral e tempo próprios. O seu tempo pode ser esticado, porque está materializado na borracha, que, tensionada, acende sua duração ao extremo, intensificando-a; a moral posta em movimento requer a mesma intensidade da vida que se abre e se esgota num instante; sua gente morena adquire um porte espigado que não 
deixa de revelar uma nobreza chã; e sua linguagem encontra-se já em estado de dilatação máxima.

Aqui se consolida o império do quatro: quatro quadras que se distribuem em dezesseis versos de oito sílabas. Acontece que nas duas estrofes nucleares, quais sejam, a segunda e a terceira, vamos encontrar a descrição simétrica de quatro dos elementos com que se constrói o seuflamenco: a cada elemento, dois versos. Ao passo que a primeira e a última estrofes tomam outra feição: a primeira, apresenta o flamenco com cinco elementos e como espaço habitável, qual uma cidade; já a última estrofe é dedicada exclusivamente ao tempo, que se materializa em borracha e não concede sono ao sujeito, porque estica o tempo da vivência, que reclama intensidade.

O curioso do enunciado é que a linguagem doflamenco, tal como foi apresentada, constitui-se por um falar com coisas do oitenta, em oposição às coisas do oito. Só não podemos esquecer que o verso é a instância material, onde melhor podemos inscrever a dicção do poeta, que, neste caso, é tomado deliberadamente como coisa estruturada em octossílabo. Noutras palavras, é como se o poeta estivesse dizendo: eu admiro e pretendo as coisas do oitenta, mas só consigo as do oito. Ou ainda, eu só vislumbro as coisas do oitenta como possibilidade em potencial, mas não como efetividade discursiva. Tratando-se de quem é o poeta, uma declaração dessas tanto pode tomar um ar irônico, quanto fatalista, se considerarmos como saldo a tradição da literatura brasileira e os descaminhos ainda não explorados de todo pela língua portuguesa.

A medida do flamenco seria, nesta proporção, o espaço almejado e até vivenciado por sua civil geometria, mas ainda não consolidado de fato, mas já apontado como limite a ser encarado. Ainda mais se voltarmos àquela compreensão desenvolvida a propósito da leitura do poema anterior em que, sob a casca formal do flamenco, encontramos uma informação preciosa para sua compreensão. Sendo esta, por si mesma, contraditória, mas que não deixa de reclamar uma certa postura de seu ouvinte, porque já configurada pelo seu cantante.

De um modo ou de outro, o poeta faz coincidir uma moralidade e seu correspondente na linguagem, não só como resultado de uma busca no poema, mas 
como tentativa de atingir, na própria expressão, a mesma especulação que o conduziu a determinados princípios. Portanto, nem a moralidade nem a linguagem que a apresenta são frutos de reinvindicações anteriores à construção da obra e tampouco uma é feita em detrimento ou à revelia da outra. Ao contrário, ambas vão se constituindo na medida em que a obra se faz, até que a linguagem adquira uma ressonância semelhante à da moral expressa, para poder assegurar a legitimidade do princípio e seu estatuto literário. Para tanto, é preciso conceber as duas dimensões emaranhadas uma na outra, para podermos averiguar, afinal, que moralidade é essa que o poeta requer para a linguagem de sua poesia, que se constitui como ética mais do que como moral, já que não cessa de pensar a si mesma a todo o instante em toda a sua duração.

Neste sentido, se a matéria é o cante flamenco, habitável e explosivo, redondilho e enquadrado, aponta mais para quem fala do que para aquilo de que se fala. As suas mesmas palavras continuam girando em torno do que é quatro, como se esse princípio valesse por si mesmo enquanto símbolo de racionalidade, que sua poesia encarna. Não é de estranhar, pois, o caráter efusivo que ele devota à cultura espanhola e, em especial à poesia dali surgida, já que através desses índices ele pode alimentar sua fixação na limpidez e dureza de seu raciocínio, que parecem melhor saciados quando convertidos em algo que se aproxime do quatro. Esta escala, sempre a postos, conduz o poeta para um lugar todo próprio, que já não é só o Recife de sua memória e nem o país estrangeiro que melhor o acolheu, mas alhures aproxima-o de uma condição bem própria do homem contemporâneo, que ainda parece ter alguma graça quando refletido nas suas palavras, porque ainda parece ser capaz de se assenhorar do universo à sua volta, enquadrando-o.

A sua realização é, portanto, algo que passa pelo filtro da racionalidade, mas não se restringe a ela como parte de uma tradição. Mas, sem desconsiderar este lado, explora-o com todas as forças como se fosse uma novidade, em que o rústico e o prosaico encontram o mesmo terreno, como se a novidade residisse no fato de astuciosamente abolir a tradição poética composta em paralelo à racionalidade, para pontencializar a ambas, aquela tradição e a racionalidade. O mais curioso é que os princípios que sustentaram a razão iluminista só precariamente parecem encontrar recurso na sua obra, senão quando transfigurados em procedimentos formais bem particulares que lhe servem de suporte. Nesta instância, já passaram a ser outra coisa nas 
palavras de João Cabral, quando cada referente adquire um novo sentido. E não podemos deixar de acreditar que esta seja uma atitude racional, só que sua racionalidade se pauta em testar todos os limites do seu próprio sujeito e, porque não, da própria racionalidade, agora convertida em discurso poético.

\section{OBRAS CITADAS}

ATAHYDE, Félix de. 1998. As idéias fixas de João Cabral de Melo Neto. Rio de Janeiro: Nova Fronteira: FBN; Mogi das Cruzes, SP: Universidade de Mogi das Cruzes.

BARBOSA, João Alexandre. 1975. A imitação da forma. São Paulo: Duas Cidades.

CARONE, Modesto. 1979. A poética do silêncio. São Paulo: Perspectiva.

CASTELlO, José. 1996. João Cabral de Melo Neto: o homem sem alma. Rio de Janeiro: Rocco.

ESCOREL, Lauro. 2001. A pedra e o rio. $2^{\mathrm{a}}$ ed. Rio de Janeiro: Academia Brasileira de Letras.

GARCIA, Othon Moacyr. 1996. Esfinge Clara e outros enigmas: ensaios estilísticos. $2^{\text {a }}$ ed. Rio de Janeiro: Topbooks.

HOUAISS, Antônio. 1976. Drummond mais seis poetas e um problema. Rio de Janeiro: Imago.

HOLANDA, Sérgio Buarque de. 1978. Cobra de vidro. 2.ed. São Paulo: Perspectiva/ Secretaria da Cultura, Ciência e Tecnologia do Estado de São Paulo.

LIMA, Luiz Costa. 1995. Lira e antilira: Mário, Drummond, Cabral. $2^{\mathrm{a}}$ ed. Rio de Janeiro: Topbooks.

MELO NETO, João Cabral de. 1994. Obra completa. Organização: Marly de Oliveira. Rio de Janeiro: Nova Aguilar.

2001. Correspondência de Cabral com Bandeira e Drummond. Organização, apresentação e notas de Flora Sussekind. Rio de Janeiro: Nova Fronteira; Fundação Casa de Rui Barbosa.

MERQUIOR, José Guilherme. 1997. A astúcia da mímese. $2^{\mathrm{a}}$ ed. Rio de Janeiro: Topbooks.

NUNES, Benedito. 1971. João Cabral de Melo Neto. Petrópolis: Vozes. 
SECCHIN, Antônio Carlos. 1999. João Cabral: a poesia do menos e outros ensaios cabralinos. $2^{\mathrm{a}}$ ed. Rio de Janeiro: Topbooks.

STEEN, Edla van. 1981. Viver e escrever. Porto Alegre: L\&PM. 